OPEN ACCESS

Edited by:

Nathan D. Wong,

University of California, Irvine,

United States

Reviewed by:

Christoph Sinning,

Universitäres Herzzentrum Hamburg

$\mathrm{GmbH}(\mathrm{UHZ})$, Germany

Hack-Lyoung Kim,

SMG-SNU Boramae Medical Center.

South Korea

*Correspondence:

David D. McManus

david.mcmanus@umassmed.edu

Specialty section:

This article was submitted to

Cardiovascular Epidemiology and

Prevention,

a section of the journal

Frontiers in Cardiovascular Medicine

Received: 17 June 2019 Accepted: 11 October 2019 Published: 30 October 2019

Citation:

McManus DD, Kiefe C, Lessard D, Waring ME, Parish D, Awad HH, Marino F, Helm R, Sogade F, Goldberg R, Hayward R, Gurwitz J,

Wang W, Mailhot T, Barton B and Saczynski J (2019) Geriatric Conditions and Prescription of Vitamin $K$ Antagonists vs. Direct Oral Anticoagulants Among Older Patients With Atrial Fibrillation: SAGE-AF. Front. Cardiovasc. Med. 6:155 doi: 10.3389/fcvm.2019.00155

\section{Geriatric Conditions and Prescription of Vitamin K Antagonists vs. Direct Oral Anticoagulants Among Older Patients With Atrial Fibrillation: SAGE-AF}

David D. McManus ${ }^{1,2 *}$, Catarina Kiefe ${ }^{1}$, Darleen Lessard ${ }^{1,2}$, Molly E. Waring ${ }^{3}$, David Parish ${ }^{4}$, Hamza H. Awad ${ }^{4}$, Francesca Marino ${ }^{2}$, Robert Helm ${ }^{5}$, Felix Sogade ${ }^{6}$, Robert Goldberg ${ }^{1}$, Robert Hayward ${ }^{7}$, Jerry Gurwitz ${ }^{8}$, Weijia Wang ${ }^{2}$, Tanya Mailhot ${ }^{9,10}$, Bruce Barton ${ }^{1}$ and Jane Saczynski ${ }^{9}$

\begin{abstract}
${ }^{1}$ Department of Population and Quantitative Health Sciences, University of Massachusetts Medical School, Worcester, MA, United States, ${ }^{2}$ Cardiology Division, Department of Medicine, University of Massachusetts Medical School, Worcester, MA, United States, ${ }^{3}$ Department of Allied Health Sciences, University of Connecticut, Mansfield, MA, United States, ${ }^{4}$ Department of Community Medicine/Internal Medicine, Mercer University School of Medicine, Macon, GA, United States, ${ }^{5}$ Department of Medicine, Boston University School of Medicine, Boston, MA, United States, ${ }^{6}$ Department of Medicine, Mercer University School of Medicine, Macon, GA, United States, ${ }^{7}$ Department of Electrophysiology, Kaiser Permanente Santa Clara Medical Center, Santa Clara, CA, United States, ${ }^{8}$ Division of Geriatric Medicine, University of Massachusetts Medical School, Worcester, MA, United States, ${ }^{9}$ Department of Pharmacy and Health System Sciences, Northeastern University, Boston, MA, United States, ${ }^{10}$ Montreal Heart Institute Research Center, Montreal, QC, Canada
\end{abstract}

Background: Geriatric conditions are common among patients with atrial fibrillation (AF) and relate to complications of oral anticoagulation (OAC).

Objective: To examine the prevalence of geriatric conditions among older patients with AF on $O A C$ and relate type of OAC to geriatric conditions.

Methods: Participants had a diagnosis of $A F$, were aged $\geq 65$ years, $\mathrm{CHA}_{2} \mathrm{DS}_{2} \mathrm{VASC}$ $\geq 2$, and had no OAC contraindications. Participants completed a 6-component geriatric assessment that included validated measures of frailty (CHS Frailty Scale), cognitive function (MoCA), social support (MOS), depressive symptoms (PHQ9), vision, and hearing. Type of OAC prescribed was documented in medical records.

Results: $86 \%$ of participants were prescribed an OAC. These participants were on average aged 75.7 (SD: 7.1) years, 49\% were women, two thirds were frail or pre-frail, and $44 \%$ received a DOAC. DOAC users were younger, had lower $\mathrm{CHA}_{2} \mathrm{DS}_{2}$ VASC and HAS-BLED scores, and were less likely to be frail. In Massachusetts, pre-frailty was associated with a significantly lower odds of DOAC vs. VKA use (OR $=0.64$, $95 \% \mathrm{Cl} 0.45,0.91)$. Pre-frailty $(O R=0.33,95 \% \mathrm{Cl} 0.18-0.59)$ and social isolation $(O R=0.38,95 \% \mathrm{Cl} 0.14-0.99)$ were associated with lower odds of DOAC receipt in patients aged 75 years or older. Social isolation was associated with higher odds of DOAC use $(O R=2.13,95 \% \mathrm{Cl} 1.05-4.29)$ in patients aged 65-74 years. 
Conclusions: Geriatric conditions were common and related to type of OAC prescribed, differentially by age group. Research is needed to evaluate whether a geriatric examination can be used clinically to better inform OAC decision-making in older patients with AF.

Keywords: atrial fibrillation, anticoagulation, frailty, social isolation, older adults

\section{INTRODUCTION}

Stroke prevention is central to atrial fibrillation (AF) treatment, and guidelines support use of oral anticoagulants (OAC) for AF patients at elevated risk for stroke (1). Three out of four AF patients aged 65 and older meet guideline criteria for OAC treatment (2).

Historically, use of an OAC for stroke prevention in $\mathrm{AF}$ meant use of a vitamin $\mathrm{K}$ antagonist (VKA). This treatment often requires frequent testing and dosing changes, since fluctuations in VKA response can result from diet, comorbid diseases, genetic variations, and drug-drug interactions. Four direct oral anticoagulants (DOACs) have been approved by the FDA for stroke prevention in non-valvular AF. These include: dabigatran, a direct thrombin inhibitor, and three factor Xa inhibitors, rivaroxaban (3), apixaban, and edoxaban (4). Recent AF management guidelines suggest that these agents be considered as first-line therapy for AF (5).

Despite the inclusion of older patients in several clinical trials comparing DOACs vs. VKA (6-8), many older patients were excluded due to comorbid illnesses. Since advanced age and common comorbidities may alter the pharmacokinetics of DOACs, the decision to prescribe a VKA or DOAC in "realworld" patients remains a conundrum. Although post-market surveillance studies show similar outcomes among DOAC and VKA-treated patients, few studies have examined differences in factors related to aging that strongly impact treatment outcomes (9). Conditions common in older patients, such as cognitive impairment, frailty, and social isolation adversely impact patient outcomes and are increasingly recognized as important components of prescribing decision making (1017). In response to accumulating data that psychosocial factors influence treatment outcomes in older patients, AHA/ACC Guidelines for AF Management (1), as well as the AHA/ACC guidelines for other cardiovascular conditions, such as AMI, include consideration of CI, depression and social support in patient management (18). Also, geriatrics-specific guidelines for acute coronary care were developed by the AHA and ACC in 2007 (19), further highlighting the increasing attention to age-related factors in the management and outcomes of CVD. Although several of these conditions have been examined for their association with AC prescribing (20), whether type of AC prescribed varies according to psychosocial and geriatric conditions has not been examined.

Using data from the ongoing Systematic Assessment of Geriatric Elements in Atrial Fibrillation (SAGE-AF) prospective cohort study, we examined the characteristics of patients treated with DOACs vs. VKAs in a "real-world" cohort of older patients with AF. The objective of this study was to examine the prevalence of geriatric conditions among older patients with AF on $\mathrm{OAC}$ and relate type of $\mathrm{OAC}$ to geriatric conditions. We hypothesized that the presence of geriatric conditions would be associated with lower odds of receiving DOACs vs. VKAs. Further, we hypothesized that geriatric conditions would have different associations with prescribing patterns in younger vs. older patients with AF.

\section{MATERIALS AND METHODS}

SAGE-AF is an ongoing study of AF, OAC treatment, and relations between geriatric conditions and clinical outcomes in adults aged 65 years and older. Consenting participants completed a comprehensive baseline geriatric assessment, a structured interview, and review of their medical records.

To be eligible for SAGE-AF, participants must have: (1) been scheduled for an ambulatory care visit at a practice in Massachusetts or Georgia, (2) had a history of AF documentation on an electrocardiogram, Holter monitor, clinic note, or hospital record, and (3) had a $\mathrm{CHA}_{2} \mathrm{DS}_{2}$ VASC risk score $\geq 2$ (indication for OAC) (2). Participants were not eligible for enrollment if they had documentation of an OAC contraindication, had an indication for OAC other than AF, did not demonstrate capacity to provide informed consent (21), did not speak English, had a planned invasive procedure with possible uncontrollable bleeding, were pregnant, were in prison, or were unwilling or unable to participate in follow-up visits at their study sites.

All participants received an invitation to participate before their clinic visit. All participants provided written consent, and all study protocols were approved by the respective Institutional Review Boards. Between June 2016 and August 2018, 1,244 patients were enrolled.

All SAGE-AF participants had a medical history and physical examination performed in the context of their routine care. Trained study staff abstracted all demographic, clinical, treatment, and laboratory characteristics from participants' medical records. All participants underwent a comprehensive interview that included a 6-component geriatric assessment using validated measures of frailty, cognitive function, social support, depressive symptoms, vision, and hearing. Frailty was assessed using the Cardiovascular Health Survey (CHS) frailty scale (22), a biological model of frailty based on five components: weight loss/shrinking; exhaustion; low physical activity (Minnesota Leisure Time Activity questionnaire) (23); slow gait speed (15foot timed walk); and weakness (grip strength). Each element receives a single point and the frailty index ranges from 0 to 5 . 
Based on the CHS scoring guidelines (22), a participant is frail if 3 or more criteria are present, pre-frail if 1 or 2 criteria are present, and not frail if 0 criteria are present.

To assess cognition, participants completed the Montreal Cognitive Assessment Battery (MoCA), a 30-item screening tool designed to assist care healthcare providers in detecting mild cognitive impairment. A cut-point of 23 was used to classify cognitive impairment (24). The 6-item Social Network Scale was used to assess the participants' social networks and a cut-point of $<12$ was used to define social isolation (25). This measure of social isolation reflects social connectedness; whether a person has friends or family members to talk to about important issues or to call when they need help. Social isolation is linked to higher rates of disability, poorer recovery from illness and death (2628). The 9-item Patient Health Questionnaire (PHQ-9) was used to assess depressive symptoms with a score of five used as a cutpoint for depressive symptoms (29). Patients self-report vision and hearing impairments $(30,31)$.

\section{STATISTICAL ANALYSIS}

We compared the characteristics of SAGE-AF participants who received OAC according to type of OAC (DOAC vs. VKA) using analysis of variance for continuous variables and chi square tests for categorical variables. We examined which geriatric elements (independent variables: cognitive function, frailty, social isolation, vision impairment, hearing impairment, depression) were associated with OAC treatment type using adjusted logistic regression analysis. In these analyses, we adjusted for each geriatric element and then additionally for clinical and demographic factors identified from univariate analyses as being associated with treatment type at the $p<0.15$ level. Differences in the clinical and treatment characteristics were noted between participants from Massachusetts and Georgia. As such, we conducted stratified regression analyses by study site and adjusted for factors associated with OAC type. We also stratified our regression analyses by age (65-74 years vs. $\geq 75$ years) since we were interested in whether geriatric conditions influenced OAC prescription choice differently among older and younger participants.

\section{RESULTS}

$86 \%$ of the 1244 SAGE-AF participants were prescribed an OAC. Of the participants prescribed an OAC, we excluded 15 participants missing data on one or more of the variables included in the analysis, resulting in an analytic sample of 1,064 older patients with AF prescribed an OAC.

Of these participants, $44 \%$ were prescribed a DOAC and $56 \%$ were prescribed VKA. Among those prescribed a DOAC, the majority received apixaban $(n=238)$ and rivaroxaban $(n=184)$, with a minority of participants receiving dabigatran $(n=40)$ or edoxaban $(n=4)$. There was a high burden of cardiovascular and non-cardiovascular comorbidities, including prior bleeding and geriatric conditions (Table 1). Women comprised about half of
TABLE 1 | Characteristics of older adults with atrial fibrillation on oral anticoagulation, according to type of oral anticoagulation: SAGE-AF, 2016-2018.

\begin{tabular}{|c|c|c|c|}
\hline Characteristic & $\begin{array}{l}\text { Direct oral } \\
\text { anticoagulant } \\
(n=466)\end{array}$ & $\begin{array}{c}\text { VKA } \\
(n=598)\end{array}$ & $p$-value \\
\hline
\end{tabular}

\section{DEMOGRAPHIC CHARACTERISTICS}

Age

65-74 years

$251(53.9)$

268 (44.8)

$<0.001$

75-84 years

$178(38.2) \quad 223(37.3)$

85 years and older

$37(7.9)$

107 (17.9)

Female

228 (48.9)

297 (49.7)

0.81

Race/Ethnicity

White

Non-White

$380(81.6) \quad 522(87.3)$

$<0.01$

Marital status ${ }^{a}$

Married or living as married

$86(18.5) \quad 76(12.7)$

Not Married

$266(57.1) \quad 327(54.7)$

0.73

Education $^{\mathrm{b}}$

High school/GED or less

Some college

College graduate

$193(41.4) \quad 261(43.7)$

$45(9.7) \quad 45(7.5)$

0.22

$209(44.9) \quad 310(51.8)$

$75(16.1) \quad 83(13.9)$

Graduate degree

$130(27.9)$

$150(25.1)$

Household income ${ }^{c}$

$>=50,000$

208 (52.0) 224 (46.0)

0.08

Insurance status ${ }^{d}$

Commercial/HMO/PPO

56 (12.0)

$128(21.4)$

$<0.01$

Medicare

$350(75.1) \quad 422(70.6)$

Other

59 (12.7)

$46(7.7)$

\section{CLINICAL CHARACTERISTICS}

\section{AF type}

Paroxysmal

Persistent

Permanent

Unknown

$\mathrm{CHA}_{2} \mathrm{DS}_{2}$ VASC score ( $\mathrm{M}, S D$ )

HAS-BLED score (M, SD)

AFEQT score (M, SD)

Bothered $^{\mathrm{e}}$ by $\geq 1$ AF symptom

in the past 4 weeks

Medical history

Acute myocardial infarction

Alcohol abuse/dependency

Anemia

Bleeding

Chronic kidney disease

Chronic lung disease

Diabetes

Heart failure

Hyperlipidemia

298 (64.0)

302 (50.5)

$<0.001$

$118(25.3) \quad 179(29.9)$

$19(4.1) \quad 50(8.4)$

$31(6.7)$

$67(11.2)$

$4.3(1.6)$

$4.7(1.6)$

$<0.01$

$2.8(1.0)$

$3.0(1.0)$

$<0.05$

78.2 (18.9)

80.5 (16.9)

$<0.05$

61 (13.2)

55 (9.2)

$<0.05$

\section{Implantable cardiac device}

Peripheral vascular disease

$\begin{array}{ccc}89(19.1) & 123(20.6) & 0.55 \\ 165(35.4) & 168(28.1) & <0.05 \\ 122(26.2) & 212(35.5) & <0.01 \\ 97(20.8) & 112(18.7) & 0.4 \\ 115(24.7) & 195(32.6) & <0.01 \\ 123(26.4) & 145(24.3) & 0.42 \\ 140(30.0) & 166(27.8) & 0.41 \\ 159(34.1) & 250(41.8) & <0.05 \\ 354(76.0) & 495(82.8) & <0.01 \\ 415(89.1) & 551(92.1) & 0.08 \\ 163(35.0) & 203(34.0) & 0.73 \\ 57(12.2) & 93(15.6) & 0.12\end{array}$

(Continued) 
TABLE 1 | Continued

\begin{tabular}{|c|c|c|c|}
\hline Characteristic & $\begin{array}{l}\text { Direct oral } \\
\text { anticoagulant } \\
(n=466)\end{array}$ & $\begin{array}{c}\text { VKA } \\
(n=598)\end{array}$ & $p$-value \\
\hline Stroke & $40(8.6)$ & 68 (11.4) & 0.13 \\
\hline Creatinine (mg/dL) M (SD) & $1.05(0.37)$ & $1.15(0.65)$ & $<0.05$ \\
\hline Hemoglobin (g/dL) M (SD) & $13.1(1.9)$ & $13.1(1.8)$ & 0.96 \\
\hline \multicolumn{4}{|l|}{ TREATMENT CHARACTERISTICS } \\
\hline Aspirin & $104(22.3)$ & $204(34.1)$ & $<0.001$ \\
\hline Clopidogrel & $30(6.4)$ & $25(4.2)$ & 0.07 \\
\hline \multicolumn{4}{|c|}{ OVERALL TREATMENT SATISFACTION } \\
\hline Extremely satisfied & $203(43.8)$ & $286(48.0)$ & 0.41 \\
\hline Very satisfied & $147(31.7)$ & $187(31.4)$ & \\
\hline Somewhat satisfied & $61(13.2)$ & $64(10.7)$ & \\
\hline Satisfied or less than satisfied & $53(11.4)$ & $59(9.9)$ & \\
\hline \multicolumn{4}{|c|}{ PSYCHOSOCIAL CHARACTERISTICS } \\
\hline Fall in past 6 months & $91(19.5)$ & $143(23.9)$ & 0.09 \\
\hline Anxiety ${ }^{\dagger}$ & $115(24.7)$ & $137(22.9)$ & 0.50 \\
\hline Living Alone & $128(27.5)$ & $167(27.9)$ & 0.87 \\
\hline Independence (IADLs) & $6.8(0.9)$ & $6.6(1.1)$ & $<0.05$ \\
\hline Confident in physician interactions ${ }^{g}$ & $302(66.8)$ & $374(64.3)$ & 0.39 \\
\hline \multicolumn{4}{|l|}{ Practice type } \\
\hline Cardiologist & $139(29.8)$ & $349(58.4)$ & $<0.001$ \\
\hline EP & $319(68.5)$ & $233(39.0)$ & \\
\hline Internist & $8(1.7)$ & $16(2.7)$ & \\
\hline
\end{tabular}

$a_{n}=17$ missing Marital Status.

${ }^{b_{n}}=17$ missing Education.

${ }^{c} n=177$ missing household income.

${ }^{d} n=3$ missing Insurance Status.

equite/extremely/very bothered with symptoms.

anxiety $G A D 7<=5$.

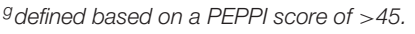

the study sample, $85 \%$ were white, two-thirds were frail or prefrail, and 22\% had suffered a fall in the last 6 months. Differences in the overall proportion of DOAC treated participants and factors associated with type of OAC prescribed were noted in Massachusetts vs. Georgia (Supplemental Table 1).

Geriatric conditions, including frailty, depression, cognitive impairment, social isolation, and visual and hearing impairments were common (Table 1, Figure 1). Given the high rate of cardiovascular comorbidity, study participants were at high risk for thromboembolic, and bleeding complications based on their $\mathrm{CHA}_{2} \mathrm{DS}_{2}$ VASC and HAS-BLED risk scores. Slightly more than three quarters (78\%) of study participants reported being satisfied or very satisfied with their overall treatment.

In comparison to participants receiving VKA, participants treated with DOACs were, on average, younger, and had lower average stroke and bleeding risk scores (Table 1). Notably, participants treated with DOACs were more likely to have paroxysmal AF, have had a symptomatic episode in the last 4 weeks, have seen a cardiologist or cardiac electrophysiologist, and have reported lower OAC burden and higher disease-specific quality of life (32). Finally, participants receiving DOACs were less likely to be frail or pre-frail and had greater independence in activities of daily living but were more likely to report social isolation.
Among participants enrolled in Massachusetts, frail, pre-frail, and cognitively impaired status were associated with 40, 46, and $35 \%$ lower odds, respectively, of being treated with DOAC (Table 2). After adjustment for stroke and bleeding risk scores as well as other factors associated with type of OAC, pre-frail status was associated with a significantly reduced odds of being prescribed a DOAC $(O R=0.64,95 \%$ CI 0.45, 0.91; Table 2). When we stratified our analyses by age, pre-frail status, and social isolation were associated with a more than $60 \%$ lower odds of DOAC-receipt in older (>75 years) participants enrolled in Massachusetts (Table 3). In contrast, low social isolation was associated with an approximately 2-fold higher rate of DOAC receipt among younger (65-74 years) participants enrolled in Massachusetts (Table 3). The sample size in Georgia was not large enough to examine these associations among patients in Georgia.

\section{DISCUSSION}

Over $80 \%$ of SAGE-AF participants were prescribed an OAC, a rate higher than has been reported in older cohorts but consistent with more recent data (33). This higher rate may also be explained by differences in the eligibility criteria used by our study, which required that participants not have active bleeding or other contraindications to OAC.

Although an increasing number of patients with $\mathrm{AF}$ are prescribed DOACs, VKAs are frequently used for stroke prevention (34). VKAs place a high burden on older patients, with dietary and lifestyle restrictions, frequent lab monitoring, and frequent dosage adjustments. We observed that $44 \%$ of anticoagulated study participants were treated with DOACs, a rate lower than has been reported in Europe and some specialized US centers (33), but slightly higher than what was reported by the IMS Health National Disease and Therapeutic Index (38\%) (35). Consistent with national prescription rates, we observed that apixaban and rivaroxaban were the most commonly prescribed DOACs. Study region and prescriber type (cardiac electrophysiologist vs. other) were associated with type of OAC used for AF (Table 1).

Clinical trials and meta-analyses have suggested that DOACs may be safer than VKA in older trial participants $(36,37)$; however, many older patients were excluded from these studies based on commonly occurring comorbidities. The decision of VKA vs. DOACs in "real-world" patients remains a conundrum, since advanced age, and common comorbidities (e.g., renal impairment) increase the risk of adverse events from both agents (38). Moreover, in contrast to VKA, reversal agents for DOACs were not widely available during the study period, an important consideration for many providers since older patients with AF are at high risk for falls and traumatic bleeding (39).

Prior studies have shown that geriatric conditions, including cognitive impairment, frailty, and depression, are associated with a higher odds of not being prescribed OAC despite being eligible $(40,41)$; however, few studies have examined relations between geriatric conditions and type of OAC selected (42, 43). We hypothesized that older, frailer participants 


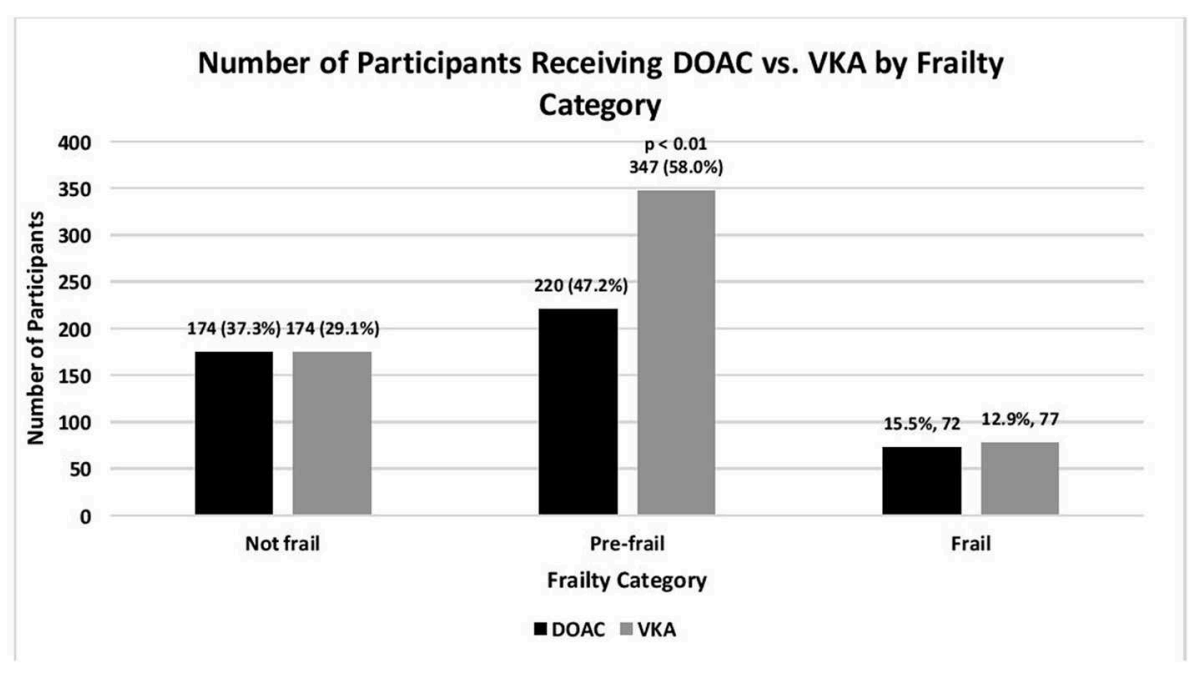

FIGURE 1 | Number of older adults with atrial fibrillation on oral anticoagulation, according to type of oral anticoagulation, and frailty category: SAGE-AF, 2016-2018. Not frail, 0 impairments; Pre-frail, 1-2 impairments; Frail, 3-5 impairments (impairments include unintentional weight loss, weakness, exhaustion, slow gait, low physical activity) as defined by the CHS Frailty Scale (22).

TABLE 2 | Receipt of DOAC vs. VKA by geriatric element status among older adults with atrial fibrillation treated with oral anticoagulation enrolled in Massachusetts $(n=818)$ : SAGE-AF, 2016-2018.

\begin{tabular}{|c|c|c|c|c|c|c|}
\hline \multirow[b]{2}{*}{ Geriatric elements } & \multirow[b]{2}{*}{$\begin{array}{c}\text { Received } \\
\text { DOAC, } N(\%)\end{array}$} & \multirow[b]{2}{*}{$p$-value } & \multicolumn{4}{|c|}{ Odds of receiving a DOAC } \\
\hline & & & $\begin{array}{l}\text { M1 unadjusted OR } \\
(95 \% \mathrm{Cl})\end{array}$ & $p$-value & $\begin{array}{l}\text { M2 adjusted OR } \\
(95 \% \mathrm{Cl})\end{array}$ & $p$-value \\
\hline \multicolumn{7}{|l|}{ Frailty } \\
\hline Frail & $29(10.4)$ & $<0.01$ & $0.60(0.37,0.99)$ & 0.41 & $0.88(0.48,1.61)$ & 0.74 \\
\hline Pre-frail & $126(45.3)$ & & $0.54(0.39,0.74)$ & $<0.05$ & $0.64(0.45,0.91)$ & $<0.05$ \\
\hline Not frail & $123(44.2)$ & & (Reference) & & (Reference) & \\
\hline Cognitive impairment & $89(32.0)$ & $<0.05$ & $0.65(0.48,0.89)$ & $<0.01$ & $0.95(0.67,1.34)$ & 0.76 \\
\hline Social isolation & $28(10.1)$ & 0.97 & $1.01(0.62,1.63)$ & 0.97 & $1.11(0.66,1.86)$ & 0.70 \\
\hline Visual impairment & $82(29.5)$ & 0.46 & $0.89(0.65,1.22)$ & 0.46 & $1.02(0.72,1.44)$ & 0.91 \\
\hline Hearing impairment & $103(37.1)$ & 0.57 & $0.92(0.68,1.24)$ & 0.57 & $1.03(0.75,1.43)$ & 0.85 \\
\hline Depression & $65(23.4)$ & 0.17 & $0.79(0.57,1.11)$ & 0.17 & $0.79(0.53,1.19)$ & 0.27 \\
\hline
\end{tabular}

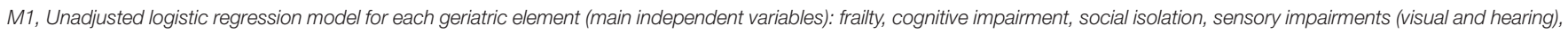

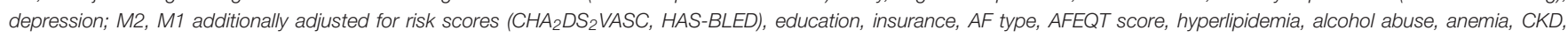
aspirin use, fall in past 6 months, IADL, provider type, frailty, and cognitive impairment. Age was accounted for via $C H A_{2} D S_{2} V A S C$.

affected by a greater burden of geriatric conditions would be prescribed VKA, since these conditions are associated with renal impairment, polypharmacy, and other age-related factors that affect DOAC treatment.

Our finding that pre-frailty status (1-2 impairments) was associated with lower odds of being treated with a DOAC supports this hypothesis. Although the association between frailty status (more than 2 impairments) and greater odds of DOAC did not achieve statistical significance, the direction of the association was the same as pre-frailty (Table 2). We suspect the lack of statistical significance may have related to the smaller number of participants in the frail (vs. pre-frail) category. Furthermore, we observed a similar but statistically more robust finding among participants aged 75 years and older, but not among younger participants (65-74 years old). This suggests that the impact of geriatric conditions on OAC prescribing may be greatest among individuals older than 75 years of age. Furthermore, social isolation was associated with a 2-fold higher rate of DOAC use among younger patients. This relationship may be explained by the benefits of social support for handling the burden of monitoring and clinical follow-up required to manage VKA. However, among the oldest participants in our cohort, social isolation was associated with $62 \%$ lower odds of DOAC receipt. This counterintuitive finding may be explained by $\mathrm{AF}$ patients or their providers perceiving frequent OAC clinic nurse evaluations 


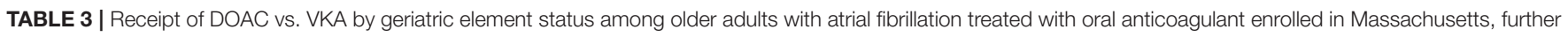
stratified by age (75-years cutoff): SAGE-AF, 2016-2018.

\begin{tabular}{|c|c|c|c|c|c|c|}
\hline Geriatric elements & DOAC N (\%) & $p$-value & M1 unadjusted OR $(95 \% \mathrm{Cl})$ & $p$-value & M2 adjusted OR (95\% Cl) & $p$-value \\
\hline \multicolumn{7}{|l|}{$<75(N=406)$} \\
\hline \multicolumn{7}{|l|}{ Frailty } \\
\hline Frail & $12(7.4)$ & & $0.60(0.28,1.26)$ & 0.27 & $0.84(0.35,2.01)$ & 0.73 \\
\hline Pre-Frail & $72(44.4)$ & 0.30 & $0.80(0.53,1.21)$ & 0.90 & $0.94(0.59,1.50)$ & 0.93 \\
\hline Not frail & $78(48.2)$ & & (Reference) & & (Reference) & \\
\hline Cognitive impairment & $45(27.8)$ & 0.84 & $0.96(0.62,1.49)$ & 0.84 & $1.39(0.84,2.31)$ & 0.20 \\
\hline Social isolation & $22(13.6)$ & 0.11 & $1.67(0.89,3.15)$ & 0.11 & $2.13(1.05,4.29)$ & $<0.05$ \\
\hline Impaired vision & $52(32.1)$ & 0.75 & $0.93(0.61,1.43)$ & 0.75 & $1.20(0.75,1.93)$ & 0.45 \\
\hline Impaired hearing & $51(31.5)$ & 0.22 & $1.32(0.85,2.05)$ & 0.21 & $1.44(0.89,2.34)$ & 0.14 \\
\hline Depression & $37(22.8)$ & 0.11 & $0.69(0.44,1.10)$ & 0.12 & $0.71(0.40,1.26)$ & 0.24 \\
\hline \multicolumn{7}{|l|}{$>=75(N=412)$} \\
\hline \multicolumn{7}{|l|}{ Frailty } \\
\hline Frail & $17(14.7)$ & $<0.01$ & $0.63(0.32,1.25)$ & 0.99 & $0.56(0.23,1.41)$ & 0.97 \\
\hline Pre-frail & $54(46.6)$ & & $0.39(0.24,0.63)$ & $<0.01$ & $0.33(0.18,0.59)$ & $<0.01$ \\
\hline Not frail & $45(38.8)$ & & (Reference) & & (Reference) & \\
\hline Cognitive Impairment & $44(37.9)$ & $<0.01$ & $0.55(0.35,0.85)$ & $<0.01$ & $0.67(0.40,1.11)$ & 0.12 \\
\hline Social isolation & $6(5.2)$ & $<0.05$ & $0.44(0.18,1.07)$ & 0.07 & $0.38(0.14,0.99)$ & $<0.05$ \\
\hline Impaired vision & $30(25.9)$ & 0.32 & $0.79(0.49,1.27)$ & 0.33 & $0.85(0.49,1.48)$ & 0.56 \\
\hline Impaired hearing & $52(44.8)$ & 0.34 & $0.81(0.53,1.25)$ & 0.35 & $0.84(0.52,1.35)$ & 0.47 \\
\hline Depression & $28(24.1)$ & 0.69 & $0.91(0.55,1.49)$ & 0.69 & $0.94(0.51,1.75)$ & 0.85 \\
\hline
\end{tabular}

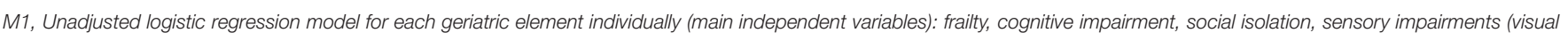

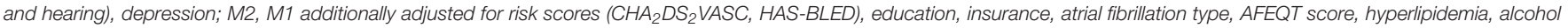
abuse, anemia, chronic kidney disease, aspirin use, fall in past 6 months, IADL, provider type, frailty, and cognitive impairment.

and/or laboratory monitoring as a potential benefit for socially isolated elders.

Our findings have important potential clinical implications. Since AF patients in the pre-frail category were more likely to receive VKA, previously published secondary data analyses suggesting that DOACs have a favorable safety profile may suffer from unmeasured confounding (43). Second, patients receiving $\mathrm{OAC}$ had high rates of geriatric conditions, placing these individuals at elevated risk for OAC complications. In contrast to patients on VKA, patients receiving DOACs for AF are infrequently followed by anticoagulation clinics, nor do they systematically receive $\mathrm{OAC}$ education. Anticoagulation clinics support providers by helping to manage AF patients and perform routine drug safety and laboratory monitoring; however, these critical care pathways are not routinely made available to DOACtreated patients.

Our findings also suggest that social isolation may influence OAC prescribing patterns and that the role of social isolation may differ among younger and older patients. Future studies should explore whether or how physicians and patients include the patient's social circumstances into conversations about treatment decision-making. Efforts to integrate support of DOAC-treated patients into traditional OAC clinics appear well-founded. Studies are needed to demonstrate that such supportive care improves patient outcomes.

The strengths of our study include the geographic diversity of the study cohort, inclusion of older AF patients with a high degree of comorbidity, and high rates of OAC use. Furthermore, the comprehensive assessment of factors associated with aging used validated and publicly available instruments that can be utilized in an office visit. Study limitations include the crosssectional nature of our analysis. Information was not available about each participant's history or duration of exposure to OAC, and participants may have recently switched from DOAC to VKA or VKA to DOAC prior to study enrollment. However, prior studies show low overall rates of switching after initial OAC prescription, particularly among DOAC-treated patients $(42,44)$. Importantly, we had limited power to evaluate the associations between geriatric elements and use of DOACs among participants in Georgia, and thus cannot conclude whether the observed point estimates for these associations are statistically significant. Further research in other large, diverse samples are needed to validate our findings, especially considering the regional variation in OAC prescribing observed in our study.

\section{CONCLUSIONS}

In a well-characterized, diverse sample of older patients with AF treated with OAC, we observed that the rates of readily assessed geriatric conditions were high and that several geriatric conditions, including pre-frailty and social isolation, were associated with a lower likelihood of receiving a DOAC. In light of guideline changes favoring DOACs over VKA for safety and effectiveness (5), additional efforts to provide tailored OAC 
education and support to frail and socially isolated patients may be necessary.

\section{DATA AVAILABILITY STATEMENT}

The datasets generated for this study will not be made publicly available as datasets contain sensitive, confidential information about study participants.

\section{ETHICS STATEMENT}

The studies involving human participants were reviewed and approved by University of Massachusetts Medical School Institutional Review Board, Boston University Institutional Review Board, and Mercer University Institutional Review Board. The patients/participants provided their written informed consent to participate in this study.

\section{AUTHOR CONTRIBUTIONS}

DM had full access to all data in the study and takes responsibility for the integrity of the data and the accuracy of the data analysis. DM, CK, MW, DP, HA, RG, JG, and JS contributed to the

\section{REFERENCES}

1. January CT, Wann LS, Alpert JS, Calkins H, Cigarroa JE, Cleveland JC, et al. 2014 AHA/ACC/HRS guideline for the management of patients with atrial fibrillation: a report of the American College of Cardiology/American Heart Association Task Force on practice guidelines and the Heart Rhythm Society. Circulation. (2014) 130:e199-267. doi: 10.1161/CIR.0000000000000040

2. Steinberg BA, Kim S, Thomas L, Fonarow GC, Hylek E, Ansell J, et al. Lack of concordance between empirical scores and physician assessments of stroke and bleeding risk in atrial fibrillation: results from the Outcomes Registry for Better Informed Treatment of Atrial Fibrillation (ORBIT-AF) registry. Circulation. (2014) 129:2005-12. doi: 10.1161/CIRCULATIONAHA.114.008643

3. Hart RG, Benavente O, McBride R, Pearce LA. Antithrombotic therapy to prevent stroke in patients with atrial fibrillation: a meta-analysis. Ann Intern Med. (1999) 131:492-501. doi: 10.7326/0003-4819-131-7-19991005 0-00003

4. Giugliano RP, Ruff CT, Braunwald E, Murphy SA, Wiviott SD, Halperin JL, et al. Edoxaban versus warfarin in patients with atrial fibrillation. $N$ Engl $J$ Med. (2013) 369:2093-104. doi: 10.1056/NEJMoa1310907

5. January CT, Wann LS, Calkins H, Chen LY, Cigarroa JE, Cleveland JC, et al. 2019 AHA/ACC/HRS focused update of the 2014 AHA/ACC/HRS guideline for the management of patients with atrial fibrillation. Circulation. (2019) 140:e125-51. doi: 10.1161/CIR.0000000000000665

6. Bansilal S, Bloomgarden Z, Halperin JL, Hellkamp AS, Lokhnygina Y, Patel $\mathrm{MR}$, et al. Efficacy and safety of rivaroxaban in patients with diabetes and nonvalvular atrial fibrillation: the Rivaroxaban Once-daily, Oral, Direct Factor Xa Inhibition Compared with Vitamin K Antagonism for Prevention of Stroke and Embolism Trial in Atrial Fibrillation. (ROCKET AF Trial). Am Heart J. (2015) 170:675-82.e678. doi: 10.1016/j.ahj.2015.07.006

7. Hu PT, Lopes RD, Stevens SR, Wallentin L, Thomas L, Alexander JH, et al. Efficacy and safety of apixaban compared with warfarin in patients with atrial fibrillation and peripheral artery disease: insights from the ARISTOTLE trial. J Am Heart Assoc. (2017) 6:e004699. doi: 10.1161/JAHA.116.004699

8. Oldgren J, Healey JS, Ezekowitz M, Commerford P, Avezum A, Pais $\mathrm{P}$, et al. Variations in cause and management of atrial fibrillation in a prospective registry of 15,400 emergency department patients in 46 countries: conception and design of the study. DL, MW, FM, and JS organized the database. DL and $\mathrm{BB}$ performed the statistical analysis. All authors had access to the data and had a role in writing the manuscript.

\section{FUNDING}

The authors declare that this study received funding from the National Heart, Lung, and Blood Institute (grant R01HL126911). DM's time was also supported by the National Heart, Lung, and Blood Institute (grant R01HL137734, R01HL137794, R01HL13660, R01HL141434, and U54HL143541). Neither the funder, nor any other party, had direct involvement with the study. The funding source was not involved in study design; collection, analysis, and interpretation of data; writing the report; or the decision to submit the article for publication. All authors have disclosed their conflicts of interest in the statement below.

\section{SUPPLEMENTARY MATERIAL}

The Supplementary Material for this article can be found online at: https://www.frontiersin.org/articles/10.3389/fcvm. 2019.00155/full\#supplementary-material the RE-LY Atrial Fibrillation Registry. Circulation. (2014) 129:1568-76. doi: 10.1161/CIRCULATIONAHA.113.005451

9. Administration. FDA Drug Safety Communication: Safety Review of Postmarket Reports of Serious Bleeding Events With the Anticoagulant Pradaxa (Dabigatran Etexilate Mesylate). (2011). Retrieved from: https://www.fda.gov/ drugs/drug-safety-and-availability/fda-drug-safety-communication-safetyreview-post-market-reports-serious-bleeding-events (accessed November $12,2018)$.

10. Bush DE, Ziegelstein RC, Tayback M, Richter D, Stevens S, Zahalsky $\mathrm{H}$, et al. Even minimal symptoms of depression increase mortality risk after acute myocardial infarction. Am J Cardiol. (2001) 88:337-41. doi: 10.1016/S0002-9149(01)01675-7

11. Frasure-Smith N, Lesperance F, Talajic M. Depression following myocardial infarction. Impact on 6-month survival. JAMA. (1993) 270:1819-25. doi: 10.1001/jama.1993.03510150053029

12. Friedmann E, Thomas SA, Liu F, Morton PG, Chapa D, Gottlieb SS. Relationship of depression, anxiety, and social isolation to chronic heart failure outpatient mortality. Am Heart J. (2006) 152:940 e941-948. doi: 10.1016/j.ahj.2006.05.009

13. Kaptein KI, de Jonge P, van den Brink RH, Korf J. Course of depressive symptoms after myocardial infarction and cardiac prognosis: a latent class analysis. Psychosom Med. (2006) 68:662-8. doi: 10.1097/01.psy.0000233237.79085.57

14. Lane D, Carroll D, Ring C, Beevers DG, Lip GY. Mortality and quality of life 12 months after myocardial infarction: effects of depression and anxiety. Psychosom Med. (2001) 63:221-30. doi: 10.1097/00006842-200103000-00005

15. Lesperance F, Frasure-Smith N, Talajic M, Bourassa MG. Five-year risk of cardiac mortality in relation to initial severity and one-year changes in depression symptoms after myocardial infarction. Circulation. (2002) 105:1049-53. doi: 10.1161/hc0902.104707

16. Lett HS, Blumenthal JA, Babyak MA, Catellier DJ, Carney RM, Berkman LF, et al. Social support and prognosis in patients at increased psychosocial risk recovering from myocardial infarction. Health Psychol. (2007) 26:418-27. doi: 10.1037/0278-6133.26.4.418

17. Ruberman W, Weinblatt E, Goldberg JD, Chaudhary BS. Psychosocial influences on mortality after myocardial infarction. N Engl J Med. (1984) 311:552-9. doi: 10.1056/NEJM198408303110902 
18. Anderson JL, Adams CD, Antman EM, Bridges CR, Califf RM, Casey $\mathrm{DE}$, et al. 2012 ACCF/AHA focused update incorporated into the ACCF/AHA 2007 guidelines for the management of patients with unstable angina/non-ST-elevation myocardial infarction: a report of the American College of Cardiology Foundation/American Heart Association Task Force on Practice Guidelines. J Am Coll Cardiol. (2013) 61:e179-347. doi: 10.1016/j.jacc.2013.01.014

19. Alexander KP, Newby LK, Armstrong PW, Cannon CP, Gibler WB, Rich MW, et al. Acute coronary care in the elderly, Part II: ST-segment-elevation myocardial infarction: a scientific statement for healthcare professionals from the American heart association council on clinical cardiology: in collaboration with the society of geriatric cardiology. Circulation. (2007) 115:2570-89. doi: 10.1161/CIRCULATIONAHA.107.182616

20. Saczynski JS, Sanghai SR, Kiefe IC, Lessard D, Marino F, Waring $\mathrm{ME}$, et al. Geriatric elements and oral anticoagulant prescribing in older atrial fibrillation patients: SAGE-AF. J Am Geriatr Soc. (2019). doi: 10.1111/jgs.16178. [Epub ahead of print].

21. Schmitt EM, Marcantonio ER, Alsop DC, Jones RN, Rogers SO, Fong TG, et al. Novel risk markers and long-term outcomes of delirium: the successful aging after elective surgery. (SAGES) study design and methods. J Am Med Dir Assoc. (2012) 13:818.e811-e810. doi: 10.1016/j.jamda.2012.08.004

22. Fried LP, Tangen CM, Walston J, Newman AB, Hirsch C, Gottdiener J, et al. Frailty in older adults: evidence for a phenotype. J Gerontol A Biol Sci Med Sci. (2001) 56:M146-56. doi: 10.1093/gerona/56.3.M146

23. Pereira MA, FitzerGerald SJ, Gregg EW, Joswiak ML, Ryan WJ, Suminski RR, et al. A collection of Physical Activity Questionnaires for health-related research. Med Sci Sports Exerc. (1997) 29:S1-205.

24. Nasreddine ZS, Phillips NA, Bédirian V, Charbonneau S, Whitehead V, Collin I, et al. The Montreal Cognitive Assessment, MoCA: a brief screening tool for mild cognitive impairment. J Am Geriatr Soc. (2005) 53:695-9. doi: 10.1111/j.1532-5415.2005.53221.x

25. Lubben J, Blozik E, Gillmann G, Iliffe S, von Renteln Kruse W, Beck JC, et al. Performance of an abbreviated version of the Lubben Social Network Scale among three European community-dwelling older adult populations. Gerontologist. (2006) 46:503-13. doi: 10.1093/geront/46.4.503

26. Heidari Gorji MA, Fatahian A, Farsavian A. The impact of perceived and objective social isolation on hospital readmission in patients with heart failure: a systematic review and meta-analysis of observational studies. Gen Hosp Psychiatry. (2019) 60:27-36. doi: 10.1016/j.genhosppsych.2019.07.002

27. Holt-Lunstad J, Smith TB, Baker M, Harris T, Stephenson D. Loneliness and social isolation as risk factors for mortality: a meta-analytic review. Perspect Psychol Sci. (2015) 10:227-37. doi: 10.1177/1745691614568352

28. Makizako H, Shimada $H$, Tsutsumimoto $K$, Lee S, Doi T, Nakakubo $\mathrm{S}$, et al. Social frailty in community-dwelling older adults as a risk factor for disability. J Am Med Dir Assoc. (2015) 16:1003.e1007-1011. doi: 10.1016/j.jamda.2015.08.023

29. Spitzer RL, Kroenke K, Williams JB. Validation and utility of a self-report version of PRIME-MD: the PHQ primary care study. Primary care evaluation of mental disorders patient health questionnaire. JAMA. (1999) 282:1737-44. doi: 10.1001/jama.282.18.1737

30. Alma MA, van der Mei SF, Melis-Dankers BJ, van Tilburg TG, Groothoff JW, Suurmeijer TP. Participation of the elderly after vision loss. Disabil Rehabil. (2011) 33:63-72. doi: 10.3109/09638288.2010.488711

31. Macphee GJ, Crowther JA, McAlpine CH. A simple screening test for hearing impairment in elderly patients. Age Ageing. (1988) 17:347-51. doi: 10.1093/ageing/17.5.347

32. Spertus J, Dorian P, Bubien R, Lewis S, Godejohn D, Reynolds MR, et al. Development and validation of the Atrial Fibrillation Effect on QualiTy-ofLife (AFEQT) Questionnaire in patients with atrial fibrillation. Circ Arrhythm Electrophysiol. (2011) 4:15-25. doi: 10.1161/CIRCEP.110.958033

33. Steinberg BA, Gao H, Shrader P, Pieper K, Thomas L, Camm AJ, et al. International trends in clinical characteristics and oral anticoagulation treatment for patients with atrial fibrillation: Results from the GARFIELD-
AF, ORBIT-AF I, and ORBIT-AF II registries. Am Heart J. (2017) 194:132-40. doi: 10.1016/j.ahj.2017.08.011

34. Mant J, Hobbs FD, Fletcher K, Roalfe A, Fitzmaurice D, Lip GY, et al. Warfarin versus aspirin for stroke prevention in an elderly community population with atrial fibrillation. (the Birmingham Atrial Fibrillation Treatment of the Aged Study, BAFTA): a randomised controlled trial. Lancet. (2007) 370:493-503. doi: 10.1016/S0140-6736(07)6 1233-1

35. Barnes GD, Lucas E, Alexander GC, Goldberger ZD. National Trends in Ambulatory Oral Anticoagulant Use. Am J Med. (2015) 128:1300-5.e1302. doi: 10.1016/j.amjmed.2015.05.044

36. Granger CB, Alexander JH, McMurray JJ, Lopes RD, Hylek EM, Hanna M, et al. Apixaban versus warfarin in patients with atrial fibrillation. $N$ Engl J Med. (2011) 365:981-92. doi: 10.1056/NEJMoa1107039

37. Makam RCP, Hoaglin DC, McManus DD, Wang V, Gore JM, Spencer FA, et al. Efficacy and safety of direct oral anticoagulants approved for cardiovascular indications: systematic review and meta-analysis. PLOS ONE. (2018) 13:e0197583. doi: 10.1371/journal.pone.0197583

38. Olesen JB, Lip GY, Hansen PR, Lindhardsen J, Ahlehoff O, Andersson C, et al. Bleeding risk in 'real world' patients with atrial fibrillation: comparison of two established bleeding prediction schemes in a nationwide cohort. J Thromb Haemost. (2011) 9:1460-7. doi: 10.1111/j.1538-7836.2011.04378.x

39. Induruwa I, Evans NR, Aziz A, Reddy S, Khadjooi K, Romero-Ortuno R. Clinical frailty is independently associated with non-prescription of anticoagulants in older patients with atrial fibrillation. Geriatr Gerontol Int. (2017) 17:2178-83. doi: 10.1111/ggi.13058

40. Oqab Z, Pournazari P, Sheldon RS. What is the impact of frailty on prescription of anticoagulation in elderly patients with atrial fibrillation? A systematic review and meta-analysis. J Atr Fibrillation. (2018) 10:1870. doi: 10.4022/jafib. 1870

41. Wilkinson C, Todd O, Clegg A, Gale CP, Hall M. Management of atrial fibrillation for older people with frailty: a systematic review and meta-analysis. Age Ageing. (2019) 48:196-203. doi: 10.1093/ageing/afy180

42. Baker CL, Dhamane AD, Mardekian J, Dina O, Russ C, Rosenblatt L, et al. Comparison of drug switching and discontinuation rates in patients with nonvalvular atrial fibrillation treated with direct oral anticoagulants in the United States. Adv Ther. (2019) 36:162-74. doi: 10.1007/s12325-018-0840-8

43. Martinez BK, Sood NA, Bunz TJ, Coleman CI. Effectiveness and safety of apixaban, dabigatran, and rivaroxaban versus warfarin in frail patients with nonvalvular atrial fibrillation. J Am Heart Assoc. (2018) 7:e008643. doi: 10.1161/JAHA.118.008643

44. Alalwan AA, Voils SA, Hartzema AG. Trends in utilization of warfarin and direct oral anticoagulants in older adult patients with atrial fibrillation. Am J Health Syst Pharm. (2017) 74:1237-44. doi: 10.2146/ajhp 160756

Conflict of Interest: DM has received research support from Apple Computer, Bristol-Myers Squibb, Boehringher-Ingelheim, Flexcon, Pfizer, Samsung, Philips Healthcare, Biotronik, and has received consultancy fees from Bristol-Myers Squibb, Pfizer, Flexcon, Boston Biomedical Associates, and Samsung.

The remaining authors declare that the research was conducted in the absence of any commercial or financial relationships that could be construed as a potential conflict of interest.

Copyright (C) 2019 McManus, Kiefe, Lessard, Waring, Parish, Awad, Marino, Helm, Sogade, Goldberg, Hayward, Gurwitz, Wang, Mailhot, Barton and Saczynski. This is an open-access article distributed under the terms of the Creative Commons Attribution License (CC BY). The use, distribution or reproduction in other forums is permitted, provided the original author(s) and the copyright owner(s) are credited and that the original publication in this journal is cited, in accordance with accepted academic practice. No use, distribution or reproduction is permitted which does not comply with these terms. 